\title{
Enhancement of Creative Thinking Skills Using a Cognitive-Based Creativity Training
}

\author{
Simone M. Ritter ${ }^{1} \cdot$ Nel Mostert ${ }^{2}$ \\ Received: 8 June 2016 / Accepted: 18 August 2016 / Published online: 7 October 2016 \\ (C) The Author(s) 2016. This article is published with open access at Springerlink.com
}

\begin{abstract}
Creative thinking skills can be considered one of the key competencies for the twenty-first century - they allow us to remain flexible and provide us with the capacity to deal with the opportunities and challenges that are part of our complex and fast-changing world. The increased focus on innovation combined with recent reports of decrements in creative performance brings attention to the need to develop creative thinking skills at both the educational and business levels. The main objective of the current project was to develop and scientifically test a brief, domain-unspecific creativity training. Undergraduate university students $(N=32)$ participated in the creativity training, which was a single session of $1.5 \mathrm{~h}$ and employed a cognitive approach (i.e., participants were shown how to apply creative thinking techniques in a systematic fashion). The effectiveness of the training was tested by means of a pre- and post-training comparison employing creativity measures that relied on divergent thinking, convergent thinking, and creative problem solving skills. To control for a possible instrumentation threat, two versions of each task were created and counterbalanced between the pre- and postmeasure across participants. Following the creativity training, improvements were observed across a variety of creative performance measures. Importantly, the creativity level of the ideas generated during the divergent thinking task improved post-training. Moreover, the findings of the current study shed light on a possible underlying mechanism for these
\end{abstract}

Simone M. Ritter

s.ritter@psych.ru.nl

1 Department of Social and Cultural Psychology, Behavioural Science Institute, Radboud University, Nijmegen, The Netherlands

2 Mostert Consultancy for Creativity and Innovation Management, Naaldwijk, The Netherlands improvements in creativity, that is, cognitive flexibility. In addition to these divergent thinking skills, the training also improved convergent thinking and produced marginal improvements in creative problem solving skills. The current findings have important implications for educational and organizational settings, as they suggest that this brief creativity training (or one employing similar cognitive techniques) could be implemented to facilitate creative thinking skills.

Keywords Creativity $\cdot$ Creativity training $\cdot$ Creative thinking techniques $\cdot$ Divergent thinking $\cdot$ Convergent thinking .

Problem solving

\section{Introduction}

Creative thinking can be considered one of the key competencies for the twenty-first century, and its effects are widespread. It allows us to fly to the moon, create art, develop computers, and cure illnesses. Creativity has not only been recognized in the sciences and the arts (Feist and Gorman 1998; MacKinnon 1962; Sternberg and Lubart 1996) but has also been shown to play an important role in everyday problem solving (Cropley 1990; Mumford et al. 1991; Runco 1994; Torrance 1971; Wallas 1926). The word creativity has its roots in the Latin term creō, which means "to create, to make," and commonly refers to the ability to generate ideas or problem solutions that are original (i.e., novel) and useful (i.e., effective) (for example, Amabile 1983; Mumford 2003; Sternberg and Lubart 1999). In addition to its function of problem solving, creativity allows us to remain flexible. Cognitive flexibility provides us with the capacity to deal with the opportunities and changes that are part of our complex and fast-changing world (Cropley 1990; Reiter-Palmon et al. 1998). Due to its crucial role in innovation, the creation of new ideas and 
problem solutions has become a key concern for most organizations and businesses (Runco 2004), and some scholars refer to today's economy as a creative economy (Florida 2002; Hawkins 2001). Supporting this trend, the US Council on Competitiveness has announced "innovation will be the single most important factor in determining [...] success through the twenty-first century" (Wince-Smith 2006).

To meet the needs of the twenty-first century, academics, business leaders, and policy makers around the world have placed creativity high on their agenda. For example, 2009 was announced "the Year of Creativity and Innovation" to facilitate creative thinking skills among the entire population (European Commission 2008). Creativity is a skill that should be fostered in all disciplines and across all intellectual and social areas (UNESCO International Bureau of Education 2014). Initiatives to facilitate creativity are especially important since a creativity crisis has been identified, revealing significant decrements in creativity since the 1990s (Kim 2011; Kimbell 2000; Newton and Newton 2010). Both the heightened focus on creativity and innovation and the overall decline in creative performance bring attention to the need to develop creative thinking skills at both the educational and business levels. Creativity was long considered a topic not open to scientific research (Sternberg and Lubart 1999; Treffinger 2009) - perhaps due to traditional beliefs that creativity has mystical origins - but in recent years, increasing insights have been gained into how creative ideas arise in the brain (e.g., see the review by Sawyer 2011). For example, it is now understood that creative thinking depends on fundamental cognitive processes, such as working memory, the ability to create new mental categories, and the ability to mentally manipulate objects (Ward et al. 1999). Creative thinking skills are thus inherent to normative cognitive functioning rather than an innate talent available to only a few genius minds. Importantly, research supports the idea that creative thinking can be trained (for a meta-analysis, see Scott et al. 2004a).

Despite the urgent need for creativity, few curriculums devote much time or attention to developing creative thinking skills; in fact, the education system often discourages it (Edwards et al. 2006). This means that often, we are trained to consume knowledge but are not taught how to produce creative ideas and solutions. This is particularly problematic when graduates enter the workforce, as they have to be prepared for the needs of our creative economy (Florida 2002; Hawkins 2001). Similarly, those already established in work during adult life need to deal with twenty-first century problems but are not taught the creative thinking skills required to solve them. As such, people of all age groups could benefit from a training that enhances creative performance. Developing, evaluating, and implementing new content into the educational curriculum, such as creative thinking skills, take significant time. A valid alternative during this transition period might be to offer a short, well- developed, and scientifically tested creativity training - one that can be implemented easily in schools and business settings.

Previous creativity training approaches have been reported to differ across four main types of variables, including the cognitive processes targeted by the training, the techniques used in the training, the media used to deliver the training, and the types of exercises used during the training (for a more thorough discussion about these categories, see the meta-analysis of creativity training types by Scott et al. 2004b). Of importance for the current study, the cluster analysis of creativity training techniques by Scott et al. (2004b), revealed four broad themes: imagery training $(N=43,27.6 \%)$, idea production training $(N=83$, $53.2 \%)$, cognitive training $(N=17,10.9 \%)$, and thinking skills training $(N=13,8.3 \%)$. Thus, cognitive training approaches were found to be relatively uncommon. Although less common than idea production training, some cognitive training approaches (e.g., conceptual combination training) were found to have larger effects and higher success rates than did idea production training. These findings, plus the meta-analysis of training effectiveness by Scott et al. (2004a), suggest that cognitive approaches will be effective, providing there is a focus on how to apply the technique (see Scott et al. 2004b). One noted disadvantage of cognitive approaches, however, is that these techniques tend to be lengthy (see Scott et al. 2004b). Thus, the length of cognitive training approaches could be a factor that limits the implementation of such creativity trainings in educational and business settings.

The aim of the current study was to develop and scientifically test a creativity training that anticipates these needs, and several requirements were specified for the training. First, it had to be domain unspecific; that is, the training could be applied in various contexts irrespective of the trainee's educational background. Second, the training had to employ a cognitive approach, as training programs that incorporate cognitive-oriented techniques have been shown to be effective (see Scott et al. 2004a). Third, the training had to be brief (a single session, not exceeding $1.5 \mathrm{~h}$ ) so that it could be implemented within an existing education program. Fourth, the current creativity training was developed by a scientist who holds a $\mathrm{PhD}$ in creativity and works as a creativity researcher, university teacher, and consultant and by a practitioner who has facilitated more than 900 creativity sessions with more than 14,000 participants worldwide. Thus, scientific insights and practical knowledge were combined when designing the training, which may strengthen the internal validity of the training (see Scott et al. 2004a). Finally, the effectiveness of the training had to be scientifically tested by means of an extensive pre- and post-training assessment of participants' creativity. We hypothesized that improvements in creative performance would be observed following the creativity training. 


\section{Materials and Methods}

\section{Participants}

A total of 32 ( 20 females) participants between the ages of 18 and 34 years old $(M=23.13, \mathrm{SD}=5.76)$ gave written informed consent to participate in the study, which was conducted according to the principles of the institutional review board (Ethics Committee Faculty of Social Sciences, Radboud University, the Netherlands) and the principles expressed in the Declarations of Helsinki. All the participants were Dutch and recruited for voluntary participation via the online research participation system (Sona) of Radboud University. The participants were from varied educational backgrounds, including MBO (EQ National Diploma or Vocational training; $n=1$ ), HAVO/VWO (EQ High School Diploma; $n=2$ ), HBO (EQ Applied Bachelor's degree; $n=2$ ), and WO (EQ University Bachelor's degree; $n=27$ ). Participants were given a choice of earning course credit ( 2.5 points) or $€ 15$ (approximately $\$ 16.70$ USD) for their participation. Finally, the creativity training took place on March 30, 2015 at the laboratory of the Behavioural Science Institute, Radboud University, the Netherlands. Participants were subdivided across three training sessions (09:00-11:30, 10 participants; 11:45-14:15, 13 participants; 14:30-17:00, 9 participants). The same procedures were used during all sessions, which were conducted by the same experimenter and creativity trainer.

\section{Design}

The overall effectiveness of the training was examined using a within-subjects design, with creative performance (pre, post) as the dependent variable. The techniques that were applied in the creativity training are described in the "Training Techniques" section, the measurement of creative performance is described in the "Measures of Creative Performance" section, and the procedure is described in the "Procedure" section.

\section{Training Techniques}

The training lasted $1.5 \mathrm{~h}$. Based on the requirements outlined in the introduction, the following techniques were incorporated in the training: Silence, lines of evolution, random connections, and SCAMPER. Each of these techniques is described in detail below.

Technique 1: Silence The participants were first provided with an explanation of the benefits of brainstorming individually and in silence. In particular, they were informed that brainstorming alone and in silence is beneficial for the creative process as it allows one to generate ideas without any restrictions, guidelines, or distractions. In addition, personal expertise and background knowledge can be used and individuals are not influenced by the ideas generated by other people. Moreover, during an individual brainstorming session, the creative thought process is not influenced by group processes (e.g., fear of criticism), idea loss due to turn-taking, and the dominance of certain group members (Nijstad and Stroebe 2006). If these group processes are at play at the beginning of a brainstorming session, the group may focus on a narrow range of idea directions - the ones mentioned by the participants who take the lead - and individual brainpower and expertise may be lost. After being introduced to the silent brainstorming technique, the participants generated ideas individually and in silence for $5 \mathrm{~min}$.

Technique 2: Lines of Evolution This technique relies on the findings of a Russian engineer, Genrikh Altshuller, who studied thousands of patents. He noticed that the evolution of breakthrough ideas - especially in the domain of technical innovation - follows universal principles. For example, a line of evolution could include changes in the form of an object using the following pattern: from solid, to powder or pieces, to liquid, to foam, to gel, to mechanics, to electronics, to spheres. A possible line of evolution for real-world inventions could be that what was once a chocolate bar can become mini chocolates or a chocolate drink, and what was once a solid \$1 coin can become a virtual bit coin. This technique may facilitate the generation of creative ideas and solutions by examining how the current form of an idea or product can be changed into the next evolutionary form, that is, by "digging deeper."

Technique 3: Random Connections Creative ideas often come from making connections between seemingly unrelated concepts or objects. Accordingly, in some situations, creative thinking may not benefit from digging deeper, but instead from "digging elsewhere." By digging elsewhere, one allows creative ideas to emerge from associative processes. The underlying approach of this technique is that one uses a random stimulus - for example, an object in the room or a picture in a newspaper - and tries to generate as many associations related to this stimulus as possible. Next, one can connect these associations to the problem that needs to be solved. To illustrate this process, imagine the following example: the problem at hand is "generate a new sun cream," and the random object chosen is a "ballpoint pen." Associations can be generated from the ballpoint pen, such as writing, color, and roller. By connecting these associations to the sun cream problem, one might generate the idea of colored sun cream (i.e., the sun cream is colored during application, which disappears once absorbed), a roll-on sun cream, or a roll-on sun cream containing colored sun cream. Thus, by facilitating the generation of random connections, this technique helps to create an environment that allows and encourages the generation of ideas that would very likely not emerge intentionally - a process which is called serendipitous creativity. The notion of serendipity is 
common throughout the history of creativity and scientific innovation, reportedly being involved in discoveries such as penicillin, the microwave, and the Post-it note.

Technique 4: Scamper During the creative process, novel solutions may emerge when forced to think of possible changes to an existing idea or product. Hereby, a list of suggestions for possible changes can be helpful. A list with seven possible thinking techniques was provided using SCAMPER (Osborn 1953; Eberle 1971), and the participants could use any or all of the suggested approaches: substitute (remove some part of the accepted situation, thing, or concept and replace it with something else), combine (join, affiliate, or force together two or more elements of your subject matter and consider ways that such a combination might move you toward a solution), adapt (change some part of your problem so that it works where it did not before), modify (consider many of the attributes and change them if necessary; attributes can include size, shape, texture, color, attitude, position), purpose (put the product to some other use), eliminate (remove any or all elements of your subject, simplify it, or reduce it to its core functionality), reverse (change the direction or orientation; turn it upside-down, inside-out, or make it go backwards/against the direction it was intended to move or be used), and rearrange (modify the order of operations or any other hierarchy involved in the product). While applying these techniques, the participants have to remember the principle of force fitting; that is, if they cannot think of anything in response to the SCAMPER prompt they are using, they have to force a response (i.e., regardless of how ridiculous it seems) and then to think of ways to make any illogical responses work.

\section{Measures of Creative Performance}

\section{Divergent Thinking: the AUT}

One of the creative skills to be developed by the current training program was divergent thinking, which is the capacity to generate multiple alternatives and solutions. There is a multitude of evidence suggesting that divergent thinking represents a distinct ability necessary for many forms of creative performance (Bachelor and Michael 1997; Mumford et al. 1998; Plucker and Renzulli 1999; Scott et al. 2004a; Scratchley and Hakstian 2001; Sternberg and O'Hara 1999; Vincent et al. 2002). Divergent thinking tests can be considered the most widely used creativity test (Cropley 2000; Davis 2003), and they are applied in approximately $40 \%$ of all creativity studies with college students and adults (Torrance and Presbury 1984). Divergent thinking can be assessed using open-ended tests, and several studies have documented its test-retest reliability (for example, see Yamamoto 1963a, 1963b). Moreover, divergent thinking tests have been recommended as tests of effectiveness for creativity trainings (DeHaan 2011).
One of the most frequently used and well-validated divergent thinking test is the Alternative Uses task (AUT, Guilford 1967). During the AUT, the participants are asked to list as many different uses for a common object as possible and to make sure that the ideas they come up with are not too common and not completely impossible. The objects used in the current study were a brick and a newspaper and they were counterbalanced between the pre- and post-measure across the participants. The participants were given $3 \mathrm{~min}$ to perform the AUT and were instructed to list their ideas in the space provided. By coding the listed ideas, the participants' creativity - the ability to generate ideas that are both novel and useful (for example, Amabile 1983; Mumford 2003; Sternberg and Lubart 1999) — was examined. Moreover, the participant's cognitive flexibility - the flexible switching among approaches - was assessed. Cognitive flexibility is characterized by global (as opposed to local) processing of information (for example, Ashby et al. 1999; Murray et al. 1990) and by the use of flat (as opposed to steep) associative hierarchies (for example, Mednick 1962). In other words, cognitive flexibility involves the ability to break cognitive patterns, to overcome functional fixedness, and to avoid a reliance on conventional ideas or solutions (Guilford 1967). Additionally, participant's fluency - the total number of ideas generated by a participant — was measured. A more detailed description of the three measures is provided below.

Creativity Each idea was assigned a creativity score, ranging from not at all creative $(=1)$ to very much creative $(=5)$. Hereby, the two essential criteria of a creative idea-novelty and usefulness (for example, Amabile 1983; Mumford 2003; Sternberg and Lubart 1999)—were taken into consideration. Two raters performed the creativity scoring. One rater assigned a creativity score to all of the ideas, and the other rater assigned creativity scores to $50 \%$ of the ideas $(50 \%$ of the ideas generated for a brick and $50 \%$ of those generated for a newspaper). The interrater reliability of the ratings was calculated using a two-way random intraclass correlation coefficient (ICC) analysis for consistency and can be considered substantial $\left(\mathrm{ICC}_{\text {BothTasks }}=0.71, \mathrm{ICC}_{\text {Krant }}=0.65, \mathrm{ICC}_{\text {Baksteen }}=0.75\right)$. For each participant, across the ideas generated, a creativity sum score was calculated. The creativity sum score can be correlated with fluency (i.e., the total number of ideas generated by a participant). To control for the possibility that quantity confounds quality (e.g., that many less original and less useful ideas get a higher score than a few highly original and highly useful ideas) mean scores were calculated for each participant by dividing their creativity sum score by their fluency score.

Cognitive Flexibility Cognitive flexibility can be quantified by the number of distinct idea categories used: each idea generated by a participant is assigned to a category from a 
predefined list of idea categories, and the total number of distinct idea categories is then calculated. For example, when asked to list possible uses for a brick, the ideas "build a house" and "build a bridge" would lead to a cognitive flexibility score of 1 , as all ideas can be assigned to the category "building something." On the other hand, the ideas build a house and "break a window" would lead to a score of 2 , as the ideas can be assigned to two different idea categories (i.e., building something, and "destroying something"). For the flexibility scoring, a list of predefined idea categories was developed by two trained raters for each of the common objects (i.e., the brick and the newspaper). One of the raters assigned all of the ideas to the predefined idea categories, while the other rater did so for $50 \%$ of the ideas (for $50 \%$ of the ideas generated for a brick and for $50 \%$ of those generated for a newspaper). The interrater reliability of the ratings was calculated using a two-way random ICC analysis for consistency and can be considered excellent $\left(\mathrm{ICC}_{\mathrm{BothTasks}}=0.97\right.$, $\left.\mathrm{ICC}_{\text {Krant }}=0.98, \mathrm{ICC}_{\text {Baksteen }}=0.95\right)$.

Fluency To calculate a participant's fluency score, the number of complete and non-redundant ideas produced was counted.

\section{Convergent Thinking: the RAT}

Although important, divergent thinking is only one component of creative thinking. Many scholars emphasize the need for an additional cognitive ability, convergent thinking; that is, the cognitive process of deriving the single best, or most correct, answer to a problem or question (Fasko 2001; Guilford 1967; Nickerson 1999; Treffinger 1995). This component of creative thought was assessed using the Remote Associates Test (RAT), which was originally developed by Mednick (1962). In the RAT, the participants are presented with three-word combinations and are required to generate a fourth word that connects the three seemingly unrelated words (e.g., bar-dress-glass, fourth word: cocktail; cocktail bar, cocktail dress, cocktail glass). The structure of the RAT - finding a highly constrained, single solution-fits well with the concept of convergent thinking. As the English RAT version is rather difficult for non-native speakers of English (e.g., Estrada et al. 1994), in the current study, the Dutch version of the RAT (adapted from Chermahini et al. 2012) was used. The participants were presented with a list of ten three-word combinations. Two versions of the RAT were provided and counterbalanced between the pre- and post-measure across participants.

\section{Creative Problem Solving}

A creative activity that requires the interplay of divergent and convergent thinking is creative problem solving-the cognitive process of searching for a novel and inconspicuous solution to a problem. Creative problem solving can be blocked by fixations - a persistent impasse in problem solving in which unwarranted assumptions, typical thinking, or recent experiences block awareness of the solution. Two common forms are perceptual and functional fixations. The participants' ability to overcome perceptual fixation was measured by a pattern perception task and the nine-dot-problem; the ability to overcome functional fixation was measured by insight tasks. Two different versions of the tasks were used and counterbalanced between the pre- and post-measure across participants.

In the pattern perception task, participants are presented with a picture consisting of various black patches on a white background and they have to indicate which pattern is presented in the picture. In the nine-dot-problem, nine dots are arranged in a square pattern. The task is to join the dots using four straight lines. Although there are no borders surrounding the task, people often feel constrained by the assumption that they must only draw within the square boundary formed by the dots. In fact, the task can only be solved if one draws outside of the square.

The insight tasks used in the current study were the twostring problem, the ball problem, the candle problem, and the switch problem. To solve these tasks, one has to use a displayed object in an unfamiliar manner (i.e., in the twostring and candle problems) or one has to complete the task in a manner which is different from prior experience or expectations (i.e., in the ball and switch problems). For example, in the two-string problem, participants are required to tie together two strings hanging from the ceiling. However, the strings are arranged so far apart that they cannot be reached at the same time. The solution requires the use of one of the objects available in the room so that one string can be set in motion as a pendulum. This swinging string can then be caught, while holding the other string, and thus can then be tied together.

\section{Demographics}

In addition to the various measures of creative performance, participants completed several demographic questions, determining the gender, age, nationality, and educational background of the participants.

\section{Procedure}

Participants were welcomed individually at the BSI entrance. Once all of the participants who were scheduled for the training session had arrived, they were accompanied to the room in which the training was held. In the training room, the experimenter briefly introduced herself and the creativity trainer and informed the participants of how the 2.5 -h session would be conducted. 
During the first $20 \mathrm{~min}$ of the session, participants' creative performance was measured (the pre-training, i.e., baseline measure) using several well-known creativity tasks (for information about the creativity tasks, see the "Measures of creative performance" section). Following the pre-training measure of creative performance, the participants received the creativity training for $1.5 \mathrm{~h}$ (for information about the training techniques, see the "Training techniques" section). The training itself started with a short word of welcome by the trainer as well as an explanation of the real-world problem that would be used for all brainstorming sessions during the training. The real-world problem required generating ideas for what the next generation sponge might look like (i.e., Hoe ziet de volgende generatie spons eruit?). For each of the four techniques, the participants completed two procedures. First, the cognitive mechanism underlying the technique and how the technique can be applied were explained to them by the trainer. Second, the participants practiced and applied the technique to the real-world problem; first alone and then in a small group (the question whether brainstorming in groups has any benefit over-and-above brainstorming individually will be addressed in a separate paper). After the training, the post-measure of creative performance was administered. The post-measure lasted $20 \mathrm{~min}$ and employed equivalent versions of the tasks used in the creativity pre-measure (i.e., the versions did not differ in the types of questions nor in level of difficulty). To control for a possible instrumentation threat (i.e., the risk that an observed change from pre- to postmeasure is due to the test that was used, rather than the training), two versions of each task were created and counterbalanced between the pre- and post-measure across participants. This meant that half of the participants performed one version as the pre-measure and the other version as the post-measure; the remaining half of the participants completed these versions in the reverse order. Finally, the participants ended the study by completing the demographic questions (for information about these questions, see the "Demographics" section). All questionnaires and training materials were provided on paper.

\section{Results}

\section{Impact of the Training on Creative Performance}

The effectiveness of the training was scientifically tested by means of a pre- and post-test, employing creativity measures that relied on divergent thinking (the "Divergent Thinking: the AUT" section), convergent thinking (the "Convergent Thinking: the RAT" section), and creative problem solving skills (the "Creative Problem Solving" section).
Divergent Thinking: the AUT

An ANOVA was performed on the mean creativity rating of ideas generated during the AUT with training (pre, post) as the within-subjects variable and task order (brick-newspaper, newspaper-brick) as the between-subjects variable. The mean creativity level of ideas produced did not differ significantly across task order group $(F(1,30)=0.092, p=.764)$, indicating that one group was not significantly more creative than the other, nor was a significant interaction effect found between task order and training $(F(1,30)=0.428, p=.518)$. Importantly, a significant main effect for training was observed $(F(1,30)=5.709, p=.023)$, suggesting that the mean creativity of the ideas generated following creativity training ( $M=2.59, \mathrm{SD}=0.45)$ was significantly higher than that of the ideas generated prior to training $(M=2.36, \mathrm{SD}=0.41)$ (see Fig. 1).

Given that a significant improvement in creative performance was found following training, it is interesting to examine the possible mechanism for the observed change. Cognitive flexibility was examined as a possible mechanism, as the training employed a cognitive approach. That is, the increase in creativity after training could be partly explained by participants diversifying the categories of their given responses (Ritter et al. 2012, 2014). As such, a $2 \times 2$ mixed ANOVA was performed on the number of distinct idea categories generated for the AUT (cognitive flexibility), with training (pre, post) as the within-subjects variable and task order (brick-newspaper, newspaper-brick) as the between-subjects variable. The analysis revealed that the cognitive flexibility of the participants in the different task order groups did not significantly differ $(F(1,30)=1.009, p=.323)$, indicating that one group did not score higher on cognitive flexibility than the other. Importantly, a main effect of the training approached significance $(F(1,30)=3.788, p=.061)$, suggesting that the

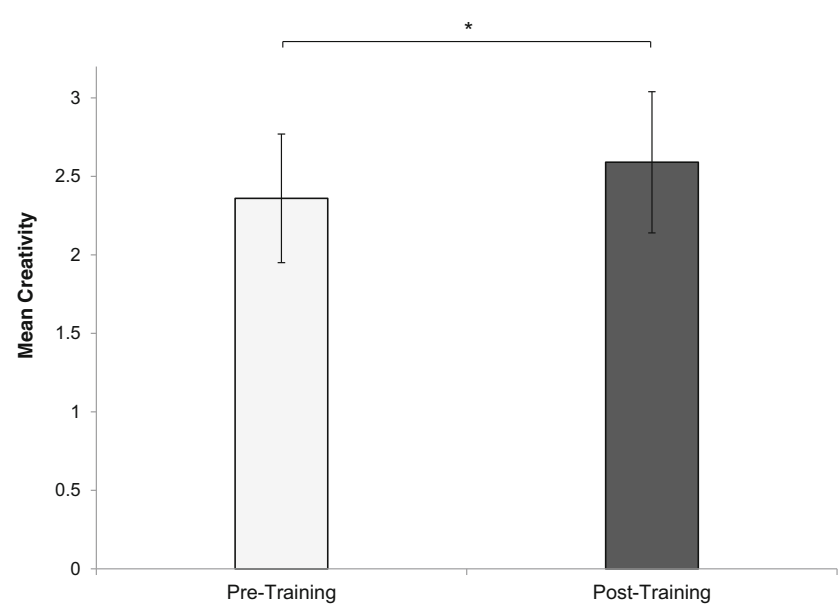

Fig 1 Mean creativity of the ideas generated pre- and post-creativity training 
mean number of idea categories generated on the AUT task could improve by approximately one distinct category from pre-training $(M=5.41, \mathrm{SD}=2.67)$ to post-training $(M=6.34$, $\mathrm{SD}=2.52$ ), see Fig. 2.

Finally, an interaction effect was found between training and task order $(F(1,30)=31.128, p<.001)$ (see Fig. 2). Post hoc analyses revealed significant differences between the two tasks before and after training, such that the number of idea categories was higher for the newspaper task both prior to training $(p<.001)$ and following training $(p=.018)$. These results suggest that generating distinct ideas might be easier for the newspaper task overall, and this was confirmed by follow-up tests - the newspaper produced a larger number of distinct idea categories $(M=7.22, \mathrm{SD}=2.73)$ compared with the brick $(M=4.53, \mathrm{SD}=1.67 ; t(31)=5.344, p<.001)$. Importantly, follow up tests revealed that performance on the more difficult task (i.e., the brick) was significantly improved from pre-training $(M=3.75, \mathrm{SD}=1.18)$ to post-training $(M=$ $7.06, \mathrm{SD}=2.74 ; t(30)=2.970, p=.006)$.

\section{Convergent Thinking: the RAT}

To examine whether the creativity training had any impact on divergent thinking, the participants' number of correctly solved RAT word pairs prior to training were compared with that following creativity training. As no participants reported prior knowledge of the RAT word pairs used, all the participant responses were included in the analysis. Initially, a mixed ANOVA was performed to include an examination of task order. However, as no significant effects involving task order were found, a within-subjects $t$ test was performed on the effect of creativity training on RAT scores (pre, post). The training appeared to have a significant impact on RAT task performance: on average, the participants solved approximately one more RAT word pair following creativity training $(M=4.73$, $\mathrm{SD}=2.32)$ compared with pre-training performance $(M=$ 3.97, $\mathrm{SD}=2.27 ; t(31)=2.342, p=.026$ ) (see Fig. 3 ).

\section{Creative Problem Solving}

To examine whether creativity training had any impact on creative problem solving skills, the problem solving performance scores prior to and following creativity training were calculated by adding the participants' scores on the picture tasks, the dot problem task, and the two insight problems. Correct responses were excluded where participants reported prior knowledge of the task(s). Given the exclusion of scores for participants who reported prior knowledge of the tasks, mean problem solving scores were also calculated (i.e., an average score for the unknown tasks completed) and examined. As the overall findings did not differ for mean or sum scores, sum scores were retained in the analysis for improved ease of interpretation. A $2 \times 2$ mixed ANOVA was performed on the problem solving score with task order as the betweensubjects variable. No significant main effect was found for task order $(F(1,30)=0.375, p=.545)$, indicating that one group was not significantly better at solving the tasks than the other. Importantly, a main effect for training approached significance $(F(1,30)=3.695, p=.064)$, such that performance on these tasks was higher following creativity training $(M=0.97, \mathrm{SD}=0.80)$ compared with performance prior to the training $(M=0.66, \mathrm{SD}=0.70)$.
Fig 2 Cognitive flexibility preand post-creativity training

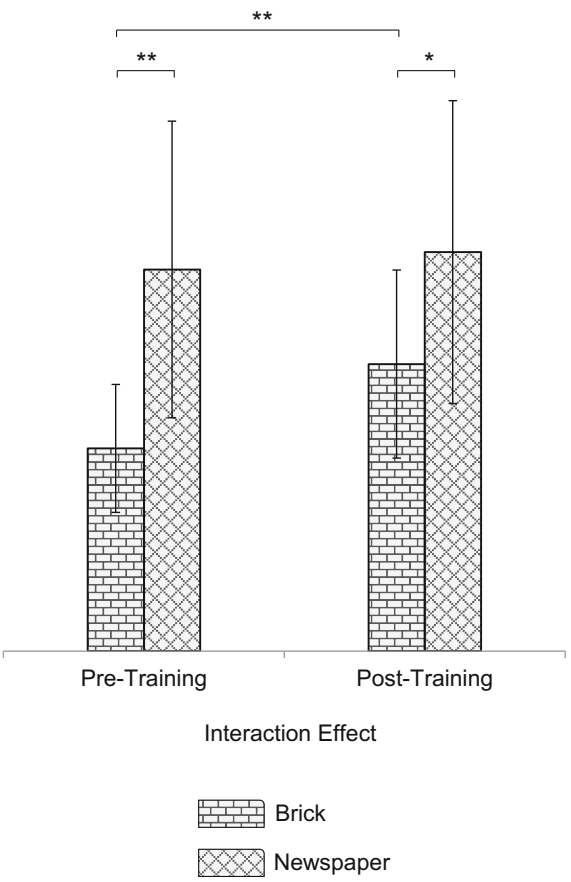




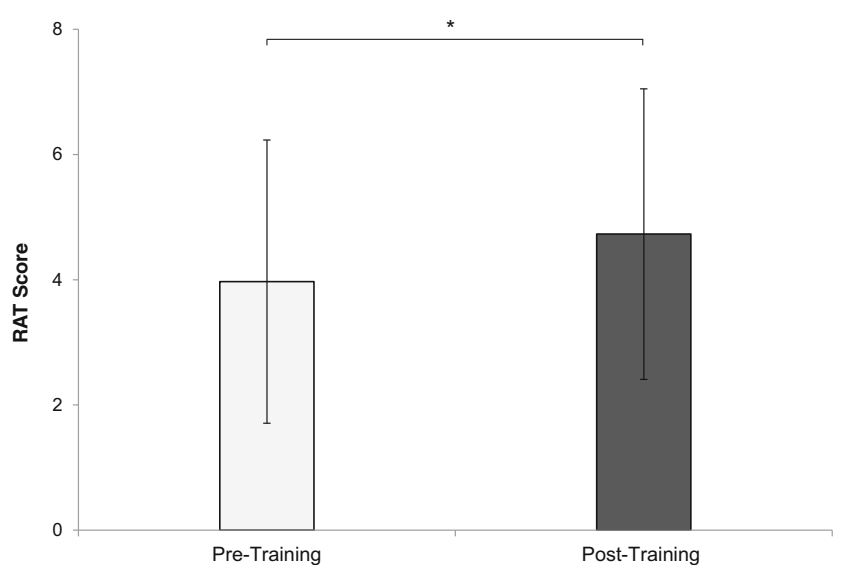

Fig 3 Performance on the RAT pre- and post-creativity training

In addition, the analyses revealed a significant interaction effect between training and task order $(F(1,30)=5.320, p=.028)$. Post hoc tests indicated that prior to training, participants who completed the problem solving task set that included the ball and rope insight tasks performed significantly better than those who completed the set containing the candle and switch tasks $(p=.041)$. Interestingly, no task order effect was observed posttraining ( $p=.387)$. Moreover, participants who completed the set of problem solving tasks including the candle and switch insight tasks prior to training showed a significant improvement in task performance post-training $(p=.006)$, while such a difference was not observed for the group who completed the problem solving tasks in the reverse order $(p=.788)$. Taken together, these results suggest that the task set containing the candle and switch tasks were harder to solve than that containing the ball and rope problems and that the training increased performance for the more difficult tasks (Fig. 4).

\section{Discussion}

\section{Summary of Research Aims and Findings}

Creativity has a crucial role in innovation, and the creation of new ideas and problem solutions has become a key concern for most organizations and businesses (Runco 2004). This goal is further supported by findings showing that creativity plays an important role in everyday problem solving (Cropley 1990; Mumford et al. 1991; Runco 1994; Torrance 1971; Wallas 1926) and in emotional health and well-being (Runco 2004; Simonton 2000). Given the importance of creativity and that creative thinking skills can be trained (Scott et al. 2004a), the goal should be to train creative skills throughout the entire population. As such, there is a strong need for a well-developed, domain-unspecific creativity training that has been scientifically tested. In addition, such creativity training would be relatively easier to implement in educational and organizational settings if it was a single, brief session. Thus, the main objectives of the current research were to develop a brief creativity training that meets these requirements and to establish whether this training can enhance creative performance.

The findings of the current study demonstrate that a short training (i.e., a single training session of just $1.5 \mathrm{~h}$ ), which develops cognitive skills necessary for creativity, can have an impact on creative performance. Following the creativity training session, improvements were observed across a variety of creative performance measures. Importantly, the creativity level of the ideas generated during the divergent thinking task improved post-training. In addition, the findings of the current study shed light on a possible underlying mechanism for these improvements in creativity, that is, cognitive flexibility. This is
Fig 4 Creative problem solving performance pre- and postcreativity training
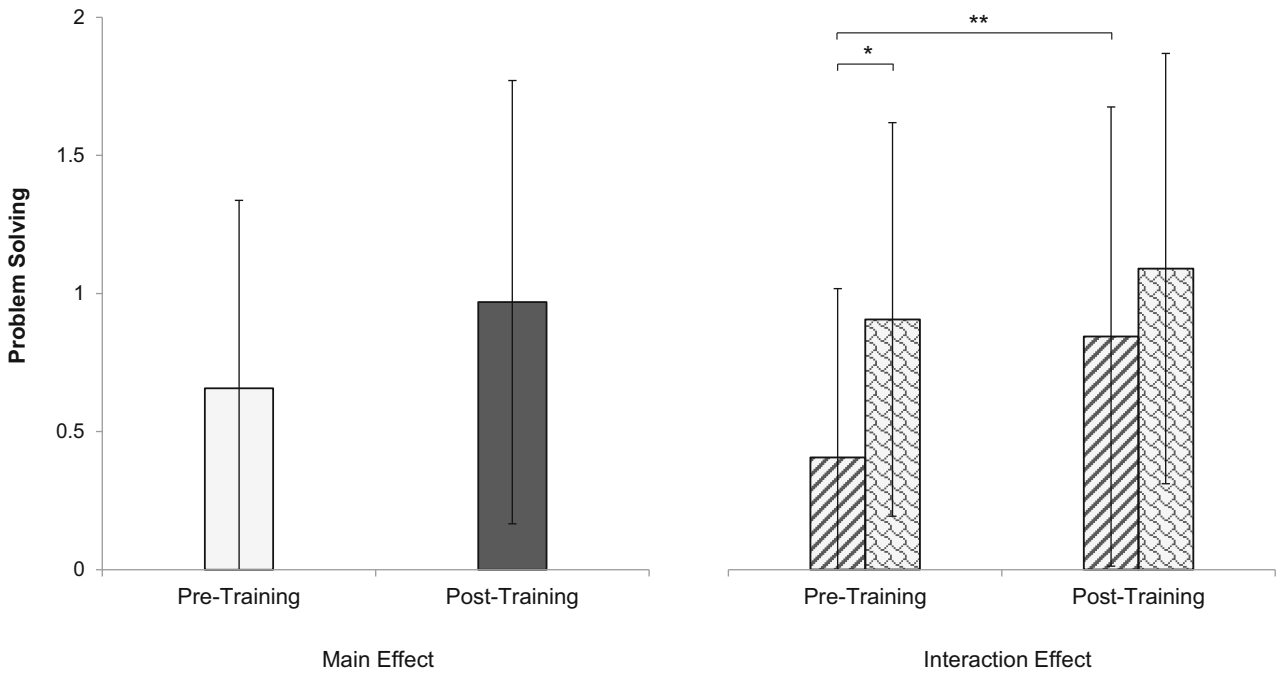

ZCandle + Switches

$\mathrm{B}$ Ball + Rope 
evidenced by a marginal improvement in the number of distinct idea categories generated post-training. Next to these divergent thinking skills, the training also improved convergent thinking, as improved performance on the RAT was observed post-training. Finally, the training provided marginal improvements in creative problem solving skills by reducing perceptual and functional fixations and mental blocks. Interestingly, it seems that the training benefitted the more difficult versions of some tasks, as demonstrated by the interaction effects for the AUT and the problem solving tasks.

The current findings provide support to the creative cognition model of creativity (for example, Ward et al. 1999), which states that individual differences in creativity can be explained by variations in the efficiency of cognitive processes underlying creativity (for example, Ward et al. 1999), and to the idea that creative thinking can be trained (Scott et al. 2004a). Moreover, the current findings have important implications for educational and organizational settings. If the goal is to train creative skills among the entire population, effective creativity training programs need to be successfully implemented - this is particularly important if we want to meet the needs of the twenty-first century. The increases in creative performance reported here are impressive and promising since the training was only short $(1.5 \mathrm{~h})$, and the effects were demonstrated across a variety of well-validated measures.

\section{Strengths and Contributions}

Previous research has shown that creativity trainings with a focus on developing cognitive skills contribute to effectiveness (Scott et al. 2004a). However, cognitive approaches tend to take longer to explain and implement and appear to be relatively less common (see Scott et al. 2004b). The current training employed a cognitive approach, with the techniques used targeting multiple divergent, convergent, and problem-solving processes (i.e., not just idea generation) (see Scott et al. 2004a, b). As such, the current creativity training makes a distinct contribution by employing a cognitive training approach in a brief, single-session, creativity training. Importantly, the exercises used during the creativity training differed from those used to evaluate the effectiveness of the training; that is, participants were not trained to the criterion (see Scott et al. 2004a). Given that significant improvements were found following the current training employing a cognitive approach, this demonstrates a transfer of cognitive skills required for creative performance - and further supports the domain-unspecific nature of the training. In line with variables thought to strengthen training quality and efficacy (see Scott et al. 2004a), the current creativity training did not include prizes, overt praise, or external motivation for creative performance.

\section{Limitations and Suggestions for Future Research}

While the current study provides evidence that the combined effects of various cognitive skills training methods work, there are some limitations of the study that should be addressed in future research. The current study included a within-subjects design with pre- and post-test creativity measures. Given the nature of the tasks included in the study, it is unlikely that the observed increase in creative performance on the postmeasure was due to practice or learned effects (e.g., different objects were used in the AUT versions and different problems were presented in the insight task versions). Moreover, interaction effects were observed for some of the creativity measures (i.e., the training benefitted the more difficult task versions), suggesting that these effects would not be improved by practice alone. However, to eliminate any practice or learned effects on creative performance with certainty, a future study could employ a between-subjects design, or a mixed design, employing a control group. In future research, it could also be interesting to investigate whether the training is particularly effective for specific creativity domains. Importantly, the current study does not allow any conclusions to be made about the long-term effects of the training. In future research, a follow-up measure could be included to gain information about the maintained effects of creativity training.

The four techniques employed in the current study were carefully selected by the authors, and it was assumed that their combined effects would have a greater impact on creative performance. It remains unclear whether just one of the training methods would be necessary to obtain these observed effects or whether their combined effects were necessary to observe significant improvements in creative performance. Future research could answer this question by examining the impact of each of these techniques on creative performance in isolation. Such a test may, moreover, provide valuable information to further improve the form of the techniques applied during the training.

Finally, the western participant sample had a high education level and a relatively high proportion of females, which could limit the ecological validity of this study. On the other hand, findings of a meta-analysis by Scott et al. (2004a) suggest that creativity training may be more effective in organizational than academic settings and may have greater effects on men than on women. Considering that this study relied on a population and setting for which the a priori chance of finding a training effect was not high, the ecological validity and generalizability of the current findings may be enhanced. However, it is still unknown what impact such training would have on eastern participants and on other age groups, for example, school-aged children and elderly people. Future research could include examining how this or a similar training can be adapted in eastern cultures and for other age groups. 


\section{Conclusions}

Creative thinking can be considered one of the key competencies for the twenty-first century and is viewed as being essential for entrepreneurial activities and long-term economic growth (Amabile 1997; Wise 1992). If a goal is to train creative thinking skills, effective creativity training programs need to be developed and successfully implemented. The current study provided further evidence that creative potential is inherent to cognitive functioning and can be facilitated with training. Impressively, following a short (a single session lasting $1.5 \mathrm{~h}$ ) domain-unspecific training, which develops cognitive skills necessary for creativity, improved creative performance on a variety of well-validated measures. These findings have important implications for educational and organizational settings, as they suggest that the present brief creativity training (or one employing similar cognitive techniques) could be implemented to facilitate creative thinking skills among the entire population.

Acknowledgments Financial support was provided by a Netherlands Organization for Scientific Research (NWO) Veni grant awarded to Simone M. Ritter (016.155.049. Veni 2014. Division Social Sciences).

We would like to thank Bernice Plant for her help with the data analysis and the writing of the paper.

Compliance with Ethical Standards A total of 32 (20 females) participants between the ages of 18 and 34 years old $(M=23.13, \mathrm{SD}=5.76)$ gave written informed consent to participate in the study, which was conducted according to the principles of the institutional review board (Ethics Committee Faculty of Social Sciences, Radboud University, the Netherlands) and the principles expressed in the Declarations of Helsinki.

Open Access This article is distributed under the terms of the Creative Commons Attribution 4.0 International License (http:// creativecommons.org/licenses/by/4.0/), which permits unrestricted use, distribution, and reproduction in any medium, provided you give appropriate credit to the original author(s) and the source, provide a link to the Creative Commons license, and indicate if changes were made.

\section{References}

Amabile, T. M. (1983). The social psychology of creativity: a componential conceptualization. Journal of Personality and Social Psychology, 45(2), 357-376. doi:10.1037/0022-3514.45.2.357.

Amabile, T. M. (1997). Motivating creativity in organizations: on doing what you love and loving what you do. California Management Review, 40(1), 39-58. doi:10.2307/41165921.

Ashby, F. G., Isen, A. M., \& Turken, A. U. (1999). A neuropsychological theory of positive affect and its influence on cognition. Psychological Review, 106(3), 529-550. doi:10.1037/0033-295 X.106.3.529.

Bachelor, P. A., \& Michael, W. B. (1997). The structure of intellect model revisited. In M. A. Runco (Ed.), The creativity research handbook: volume 1 (pp. 155-182). New York: Hampton Press.

Chermahini, S. A., Hickendorff, M., \& Hommel, B. (2012). Development and validity of a Dutch version of the remote associates task: an item-response theory approach. Thinking Skills and Creativity, 7(3), 177-186. doi:10.1016/j.tsc.2012.02.003.

Cropley, A. J. (1990). Creativity and mental health in everyday life. Creativity Research Journal, 3(3), 167-178. doi:10.1080 /10400419009534351.

Cropley, A. J. (2000). Defining and measuring creativity: are creativity tests worth using? Roeper Review, 23(2), 72-79. doi:10.1080 /02783190009554069.

Davis, G. A. (2003). Identifying creative students, teaching for creative growth. In N. Colangelo \& G. A. Davis (Eds.), Handbook of gifted education (pp. 311-324). Boston: Allyn and Bacon.

DeHaan, R. L. (2011). Teaching creative science thinking. Science, 334(6062), 1499-1500. doi:10.1126/science.1207918.

Eberle, R. (1971). SCAMPER games for imagination development. New York: DOK Publications.

Edwards, M., McGoldrick, C., \& Oliver, M. (2006). Creativity and curricula in higher education: academics' perspectives. In N. Jackson, M. Oliver, M. Shaw, \& J. Wisdom (Eds.), Developing creativity in higher education: an imaginative curriculum (pp. 59-73). London: Routledge.

Estrada, C. A., Isen, A. M., \& Young, M. J. (1994). Positive affect improves creative problem solving and influences reported source of practice satisfaction in physicians. Motivation and Emotion, 18, 285-299.

European Commission. (2008). 2009, European year of creativity and innovation. Retrieved from http://www.create2009.europa.eu

Fasko, D. (2001). Education and creativity. Creativity Research Journal, 13(3-4), 317-327. doi:10.1207/S15326934CRJ1334 09.

Feist, G. J., \& Gorman, M. E. (1998). The psychology of science: review and integration of a nascent discipline. Review of General Psychology, 2(1), 3-47. doi:10.1037/1089-2680.2.1.3.

Florida, R. (2002). The raise of the creative class: and how it's transforming work, leisure, community and everyday life. New York: Basic Books.

Guilford, J. P. (1967). Creativity: yesterday, today and tomorrow. Journal of Creative Behavior, 1(1), 3-14. doi:10.1002/j.2162-6057.1967. tb00002.x.

Hawkins, J. (2001). The creative economy: how people make money from ideas. London: Allen Lane.

Kim, K. H. (2011). The creativity crisis: the decrease in creative thinking scores on the torrance tests of creative thinking. Creativity Research Journal, 23(4), 285-295. doi:10.1080/10400419.2011.627805.

Kimbell, R. (2000). Creativity in crisis. Journal of Design and Technology Education, 5(3), 206-211.

MacKinnon, D. W. (1962). The nature and nurture of creative talent. American Psychologist, 17(7), 484-495. doi:10.1037/h0046541.

Mednick, S. (1962). The associative basis of the creative process. Psychological Review, 69(3), 220-232. doi:10.1037/h0048850.

Mumford, M. D. (2003). Where have we been, where are we going? Taking stock in creativity research. Creativity Research Journal, 15(2-3), 107-120. doi:10.1080/10400419.2003.9651403.

Mumford, M. D., Mobley, M. I., Reiter-Palmon, R., Uhlman, C. E., \& Doares, L. M. (1991). Process analytic models of creative capacities. Creativity Research Journal, 4(2), 91-122. doi:10.1080 /10400419109534380.

Mumford, M. D., Marks, M. A., Connelly, M. S., Zaccaro, S. J., \& Johnson, J. F. (1998). Domain-based scoring in divergent-thinking tests: validation evidence in an occupational sample. Creativity Research Journal, 11(2), 151-163. doi:10.1207/s15326934 crj1102 5 .

Murray, N., Sujan, H., Hirt, E. R., \& Sujan, M. (1990). The influence of mood on categorization: a cognitive flexibility interpretation. Journal of Personality and Social Psychology, 59(3), 411-425. doi:10.1037/0022-3514.59.3.411.

Newton, L. D., \& Newton, D. P. (2010). What teachers see as creative incidents in elementary science lessons. International Journal of 
Science Education, 32(15), 1989-2005. doi:10.1080 /09500690903233249.

Nickerson, R. S. (1999). Enhancing creativity. In R. J. Sternberg (Ed.), Handbook of creativity (pp. 392-430). Cambridge: Cambridge University Press.

Nijstad, B. A., \& Stroebe, W. (2006). How the group affects the mind: a cognitive model of idea generation in groups. Personality and Social Psychology Review, 10(3), 186-213. doi:10.1207/s15327957 pspr1003_1.

Osborn, A. F. (1953). Applied imagination: principles and procedures of creative problem-solving. New York: Scribners.

Plucker, J. A., \& Renzulli, J. S. (1999). Psychometric approaches to the study of human creativity. In R. J. Sternberg (Ed.), Handbook of creativity (pp. 35-61). Cambridge: Cambridge University Press.

Reiter-Palmon, R., Mumford, M. D., \& Threlfall, K. V. (1998). Solving everyday problems creatively: the role of problem construction and personality type. Creativity Research Journal, 11(3), 187-197. doi:10.1207/s15326934crj1103 1.

Ritter, S. M., Damian, R. I., Simonton, D. K., van Baaren, R. B., Strick, M., Derks, J., et al. (2012). Diversifying experiences enhance cognitive flexibility. Journal of Experimental Social Psychology, 48(4), 961-964. doi:10.1016/j.jesp.2012.02.009.

Ritter, S. M., Kühn, S., Müller, B. C., Van Baaren, R. B., Brass, M., \& Dijksterhuis, A. (2014). The creative brain: corepresenting schema violations enhances TPJ activity and boosts cognitive flexibility. Creativity Research Journal, 26(2), 144-150. doi:10.1080 /10400419.2014.901061.

Runco, M. A. (1994). Problem finding, problem solving, and creativity. California: Greenwood Publishing Group.

Runco, M. A. (2004). Everyone has creative potential. In R. J. Sternberg \& E. L. Grigorenko (Eds.), Creativity: from potential to realization (pp. 21-30). Washington, D.C.: American Psychological Association.

Sawyer, K. (2011). The cognitive neuroscience of creativity: a critical review. Creativity Research Journal, 23(2), 137-154. doi:10.1080 /10400419.2011.571191.

Scott, G., Leritz, L. E., \& Mumford, M. D. (2004a). The effectiveness of creativity training: a quantitative review. Creativity Research Journal, 16(4), 361-388. doi:10.1080/10400410409534549.

Scott, G., Leritz, L. E., \& Mumford, M. D. (2004b). Types of creativity training: approaches and their effectiveness. Journal of Creative Behavior, 38(3), 149-179. doi:10.1002/j.2162-6057.2004.tb01238.x.

Scratchley, L. S., \& Hakstian, A. R. (2001). The measurement and prediction of managerial creativity. Creativity Research Journal, 13(34), 367-384. doi:10.1207/S15326934CRJ1334_14.
Simonton, D. K. (2000). Methodological and theoretical orientation and the long-term disciplinary impact of 54 eminent psychologists. Review of General Psychology, 4(1), 13-24. doi:10.1037/1089-2680.4.1.13.

Sternberg, R. J., \& Lubart, T. I. (1996). Investing in creativity. American Psychologist, 51(7), 677-688. doi:10.1037/0003-066X.51.7.677.

Sternberg, R. J., \& Lubart, T. I. (1999). The concept of creativity: prospects and paradigms. In R. J. Sternberg (Ed.), Handbook of creativity (pp. 3-15). Cambridge: Cambridge University Press.

Sternberg, R. J., \& O’Hara, L. A. (1999). Creativity and intelligence. In R. J. Sternberg (Ed.), Handbook of creativity (pp. 251-272). Cambridge: Cambridge University Press.

Torrance, E. P. (1971). Are the torrance tests of creative thinking biased against or in favor of "disadvantaged" groups? Gifted Child Quarterly, 15(2), 75-80. doi:10.1177/001698627101500201.

Torrance, E. P., \& Presbury, J. (1984). The criteria of success used in 242 recent experimental studies of creativity. Creative Child \& Adult Quarterly, 9(4), 238-242.

Treffinger, D. J. (1995). Creative problem solving: overview and educational implications. Educational Psychology Review, 7(3), 301-312. doi:10.1007/BF02213375.

Treffinger, D. J. (2009). Myth 5: creativity is too difficult to measure. Gifted Child Quarterly. doi:10.1177/0016986209346829.

UNESCO International Bureau of Education (2014). Creativity. In Guiding Principles for Learning in the Twenty First Century (p. 15 - 18). Retrieved from www.ecolint.ch/file/621 /download?token=zhQHu7qg.

Vincent, A. S., Decker, B. P., \& Mumford, M. D. (2002). Divergent thinking, intelligence, and expertise: a test of alternative models. Creativity Research Journal, 14(2), 163-178. doi:10.1207/S15326934 CRJ1402 4.

Wallas, G. (1926). The art of thought. New York: Harcourt Brace.

Ward, T. B., Smith, S. M., \& Finke, R. A. (1999). Creative cognition. In R. J. Sternberg (Ed.), Handbook of creativity (pp. 189-212). Cambridge: Cambridge University Press.

Wince-Smith, D. L. (2006). The creativity imperative: a national perspective. Peer Review, 8(2), 12.

Wise, G. (1992). Inventor and corporations in the maturing electrical industry. In R. J. Weber \& D. N. Perkins (Eds.), Inventive minds: creativity in technology (pp. 291-310). Oxford: Oxford University Press.

Yamamoto, K. (1963a). Creative writing and school achievement. School and Society, 91, 307-308.

Yamamoto, K. (1963b). Relationships between creative thinking abilities of teachers and achievement and adjustment of pupils. The Journal of Experimental Education, 32(1), 3-25. doi:10.1080 /00220973.1963.11010803. 